\title{
7
}

\section{Cerebral Venous Thrombosis in Patients Using Oral Contraceptives}

\author{
Procházka Václav¹, Procházka Martin², \\ L'ubušký Marek², Procházková Jana ${ }^{3}$ and Hrbáč Tomáš 4 \\ ${ }^{1}$ Radiodiagnostic Institute FN Ostrava-Poruba \\ ${ }^{2}$ Gynaecology and Obstetrics Department FN and LF UP Olomouc \\ ${ }^{3}$ Haemato-oncology Department FN and LF UP Olomouc \\ ${ }^{4}$ Neurosurgery Department FN Ostrava-Poruba \\ Czech Republic
}

\section{Introduction}

Cerebral venous thrombosis is a relatively rare, however life-threatening condition. Current studies show that around $10 \%$ of the patients die. Earlier works proved that most of the thromboses originated secondarily, as a consequence of local or systemic infection, more than $30 \%$ of the cases were considered to be idiopathic. More recent studies also mention other risk factors, which may contribute to the onset of thrombosis. These include thrombophilic states or use of oral contraceptives. A number of hypercoagulation states or thrombophilic conditions, which contribute to the onset of thromboembolic disease, have been discovered and described in the recent years.

Thrombophilia is a congenital or acquired disorder of the haemostatic mechanism, characterized with an increased tendency towards blood clotting and thrombotization. Typical manifestations of the condition include frequent occurrence of lower extremities thromboses in young age, with frequent recurrence, or localization in unusual places. Congenital forms of the disorder are characterized with family occurrence. The most frequent conditions associated with congenital form of the disease are mutation of genes coding VLeiden factor (Leiden mutation), prothrombin G20210A, hyperhomocysteinemia and furthermore also autosomal inheritance of antithrombin III (AT III), protein C and protein S deficit.

The point mutation of the factor $\mathrm{V}$ gene usually occurs in the place of protein $\mathrm{C}$ binding, which results in its cleavage and inactivation. The changes are associated with substitution of guanine with adenine at the 1691st nucleotide of the factor $\mathrm{V}$, this substitution results in further substitution of glutamine with arginine on the $506^{\text {th }}$ position of the factor $\mathrm{V}$ chain (FV Q506). The mutation is also known as "Leiden mutation", based on the place of its discovery (Leiden, Holland). Substitution of amino acids in the factor $\mathrm{V}$ chain causes resistance against the activated protein C, resulting in a higher tendency towards thrombosis. The mutation is considered to be autosomal dominant hereditary. It affects 5-9\% of the European population. The mechanism of resistance against the activated protein $\mathrm{C}$ (APC resistance) was first described by Dahlbäck in 1993 in Sweden.

Another possible predisposition factor of venous thrombosis is a mutation of gene for prothrombin - G20210A variant. It is present in about $2 \%$ of the population. The mutation 
causes an increase of the prothrombin level and contributes to elevation of the risk of thrombosis up to threefold level.

Deficit of the antithrombin III is a disorder with most prothrombotic effects. The risk of developing a thromboembolic disease during life is $70-80 \%$ in carriers in the heterozygous form (homozygous carriers suffer from a lethal thromboembolic event usually already during childhood). AT III is a polypeptide synthetized in hepatocytes with an increased half-time (65 hours). Apart from its effect on thrombin, AT III is also able to activate factors $\mathrm{Xa}, \mathrm{IXa}, \mathrm{VII}$ a and plasmin. The activation of antithrombin III is increased up to 40000 times with heparin binding. The deficit of AT III is caused by numerous point mutations, deletion and insertion, and the inheritance is mostly autosomally dominant.

Homocysteine is contained in plasma at concentrations of $5-16 \mu \mathrm{mol} / \mathrm{l}$. Congenital hyperhomocysteinemia may be caused by a number of enzymatic defects. Clinical manifestations may be strengthened with a deficit of B6 and B12 vitamins, folic acid or during a treatment with methotrexate. Thrombophilia caused by hyperfibrinogenemia and dysfibrinogenemia is observed significantly less frequently.

Large population studies aimed at the relations between hormonal contraceptives and deep vein thrombosis have been performed. The increased risk was described mainly in patients using third-generation gestagens. Moreover, the identified risk of thrombosis in patients using hormonal contraceptives with thrombophilia is higher than what would correspond with a simple addition of risks. This finding confirms the theory that the procoagulation mechanisms are mutually strengthened in these women.

The problems of cerebral venous thrombosis in women in fertile age, who are the users of hormonal contraceptives have been studied in several trials including only a small number of patients. The results are in many cases misleading and inconsistent.

The aim of our study was to analyse cases of CVT in relation to sex, age, use of hormonal contraceptives and thrombophilic states, in correlation with CT, MRI and DSA findings and with clinical neurological findings.

\section{Clinical study}

We present a set of eight cases of women with a diagnosed cerebral venous thrombosis. The age scope of the group was 18.7 - 39.3 years of age, with mean of 28.1 years. The patients were hospitalized between April 2004 and October 2005. All patients were referred to CT / MRI and DSA venography examinations. Five of the women were treated with a therapeutic dose of low-molecular heparins (LMWH) only, with a transfer to warfarin treatment, other three patients underwent an interventional treatment with local thrombolysis with Actilyse ${ }^{\circledR}$ (rt-PA), following an ineffective LMWH application.

We have evaluated all medical records of the patients, the patients were examined physically and we have taken a detailed history record. Seven patients were using thirdgeneration hormonal contraceptives with gestagens, one patient was using purely gestagen contraceptives, none of the patients smoked.

\section{Laboratory examinations}

All patients were referred for blood tests in order to define the presence of thrombophilic states. The blood samples were collected and tested prior to the onset of an anticoagulation treatment, and 3-6 months following a thrombotic event. 
APC resistance was tested with the use of factor V deficient plasma (Coatest ${ }^{\circledR}$ APC resistance Chromogenix). The test presents almost $100 \%$ sensitivity and specificity in detection of factor $\mathrm{V}$ mutations (Leiden). Patients with APC ratio below 1.86 were tested with PCR analysis for the presence of $\mathrm{FV}: \mathrm{Q}^{506}$ allele. We have also chromatogenously determined the levels of protein $\mathrm{C}$, antithrombin III (AT III), prothrombin, heparin II cofactor and plasminogen. Protein S was determined immunologically, as a free form of protein $\mathrm{S}$.

In order to determine the complex mutations of FV 1691 G-A, prothrombin 20210 G-A and MTHFR 677 C-T, we used specific, polymerase chain reaction (MS PCR), according to the works of Austrian authors Endler et al. This method is a single-tube PCR technique based upon the use of allele-specific primers, differing mutually in 8-10 pairs of bases (bp). The subsequent amplification was carried out in accordance with the protocol, which was optimised for thermocycler Perkin Elmer 2400. Following the initial 10-minute denaturation at $95^{\circ} \mathrm{C}, 34$ cycles follow, consisting of separation of DNA chains for 1 min at $95^{\circ} \mathrm{C}$, annealing primers for $2 \mathrm{~min}$ at $56^{\circ} \mathrm{C}$ and DNA synthesis for $1 \mathrm{~min}$ at $72^{\circ} \mathrm{C}$. After completion, final elongation was carried out for $7 \mathrm{~min}$ at $72^{\circ} \mathrm{C}$, followed with cooling to $4^{\circ} \mathrm{C}$. To separate the PCR products we used electrophoresis on Spreadex 400 gel (Elchrom Scientific), which enables separation of products up to $400 \mathrm{pb}$, with high resolution. The results were reviewed on UV review table at $254 \mathrm{~nm}$, the photo documentation was obtained using a yellow filter with Mitsubishi camera enabling digital recording.

\subsection{Case Report of CVT - Application of local fibrinolysis in 24-year patient using HAK} 24-year-old female patient with a negative history, including pregnancy or thromboembolism used third-generation gestagen as oral contraceptives. The patient was admitted to Neurology ICU, suffering from a strong headache, localized retroaurically, lasting for the period of one week. During the previous two days, the pain was associated with vomiting. Neurological findings included IV-degree somnolence, apathy, dysarthria, nuchal rigidity with 12 points on the GCS (Glasgow Coma Scale) on admission. A CT examination and conventional DSA were carried out in the evening. Angiography showed a partial thrombotic closure of the superior sagittal sinus and complete closure of right-hand lateral and sigmoid sinus, Galen's vein and direct sinus with stagnation of venous drainage in thalamus and basal ganglia. CT examination confirmed hypodensity in the right side of the thalamus and basal ganglia, oedema in right-hand temporal-occipital area and a minor haemorrhage in the area of right lateral and sigmoid sinus.

\section{Neurological examination}

The examination showed left-hand hemiparesis, divergent strabismus, bilateral miosis, nuchal rigidity and tachycardia $120 / \mathrm{min}$. Oedema of the papillae was not present. Considering the progreding disorder of consciousness gradating into coma, the patient was intubated and left on artificial ventilation. Consequently, the patient was taken to Anaesthesiology-Resuscitation Department. We introduced anticoagulation treatment with dalteparine $1000 \mathrm{IU} / \mathrm{hr}$ and antibiotic therapy with amoxyciline with clavulanic acid 1,2 g/ $8 \mathrm{hrs}$ and ciprofloxacine $100 \mathrm{ml} / 12 \mathrm{hrs}$. The ventilation was maintained with FiO2 0,3, tidal volume (Vt) $550 \mathrm{ml}$ and positive end-expiratory pressure (PEEP) of $5 \mathrm{~cm} \mathrm{H} 20$. ECG was normal, without any ischemic signs, frequency $120 / \mathrm{min}$. Magnetic resonance and magnetic resonance venography (MRV) confirmed vasogenic inflation, blood hypovolemia of the right mesencephalum, right thalamus and basal ganglia, as well as thrombosis of deep cerebral veins and venous sinuses. 


\section{Laboratory examination}

Creatinine 63,6 umol/l, glucose 6,1 mmol/1, coagulation: INR 1,41, fibrinogen 4,69 g/l, D dimers elevated 6 -fold, protein C $45 \%$, free protein S 56\%, APC resistance negative- 4,791, AT III- 74\%, factor II 76\%, factor VIII - $112 \%$ (\% of the standard).

Despite the use of conventional anticoagulation treatment and anti-oedematous therapy according to the protocol, the serious brain stem symptoms progreded on the $5^{\text {th }}$ day after admission, associated with a loss of vertical and horizontal oculocephalic reflexes. The patient was referred to interventional centre for endovascular treatment of cerebral venous thrombosis. After admission, a control DSA examination with three-dimensional venography (3D-XRV) was carried out, with reconstruction of the venous phase. We found an incomplete thrombotic closure of both venae cerebri internae, Galen's vein and direct sinus, as well as a complete thrombosis of the right transversal and sigmoid sinuses. On the basis of this imaging examination, we decided to proceed with a local thrombolysis with rt-PA.

\section{Technique of the procedur}

5F Terumo loader (Radiofocus, Tokyo) was inserted into the common femoral vein for the purpose of a venous approach, and another $5 \mathrm{~F}$ Terumo loader was inserted retrogradely into common femoral artery for angiography imaging of the right-side carotid basin. Control position digital subtraction angiography was carried out with the 4F Vertebral Aqua - Tempo catheter (Cordis - Endovascular, JJ, Miami, FL), with 3D-Xra reconstruction of the venous phase, with the outcome of a complete thrombolysis of the basal Rosenthal's and Galen's veins, sinus rectus, sinus transversus, sinus sigmoideus and right jugular vein (Fig. 1). The patient received unfractionated Heparin in the dose of $5000 \mathrm{U}$ i.a. Another $4 \mathrm{~F}$ Vertebral Aqua Tempo catheter was inserted into the right $\mathrm{v}$. jugularis interna, using the Terumo $035^{\prime} / 260 \mathrm{~cm}$ loader (Radiofocus, Tokyo, Japan), and subsequently smoothly through the thrombus up to the area of confluens sinuum (Fig. 2). We have initiated local continuous thrombolysis on the $5^{\text {th }}$ day after admission, using the application of rtPA in the dose of $0,6 \mathrm{mg} / \mathrm{hr}$, with continuous application of UF Heparin in the dose of $700 \mathrm{IU} / \mathrm{hr}$, to reach the therapeutic levels of anticoagulation therapy. Fibrinogen, aPTT, blood count and the count of thrombocytes were monitored in 6-hour intervals. The thrombolytic treatment lasted for a total of 48 hours.

Control angiography with 3D-XRA venography performed on the $7^{\text {th }}$ day confirmed recanalization of both cerebri internae, basal Rosenthal's vein, Galen's vein, sinus rectus, transversal and sigmoid sinuses, as well as v. jugularis interna, with a rapid drainage into cortical collectors. Thrombolytic therapy was terminated after the restoration of venous flow. Control CT examination excluded bleeding complications, and subsequent MRI examination confirmed regression of hyperaemia in the area of thalamus and right basal ganglia.

During the following two days, the patient wakes from the comatose state, with further diminishing of clinical symptomatology in the following period. The NIHSS scale was scored at 4 points on the $7^{\text {th }}$ day after the interventional procedure. During a follow-up check after one month, the patient is fully self-sufficient, with mRs -0 points. The examination aimed at thrombophilic states verified heterozygous form of MTHFR: A/V 223 and homozygous form of PAI-I 4G/5G genotype mutation. The patient was introduced to anticoagulation treatment with warfarin, with periodical monthly INR check-ups. Subsequent neuro-psychological examination confirmed an excellent outcome: WAIS-R:IQ global test 141, verbal 128 and nonverbal 146 points, with Wechsler memory quotient MQ 101, pointing towards high intellectual functions. The examination further confirmed a high psychomotor speed, optimal verbal expression and memory functions at three months after the treatment. 

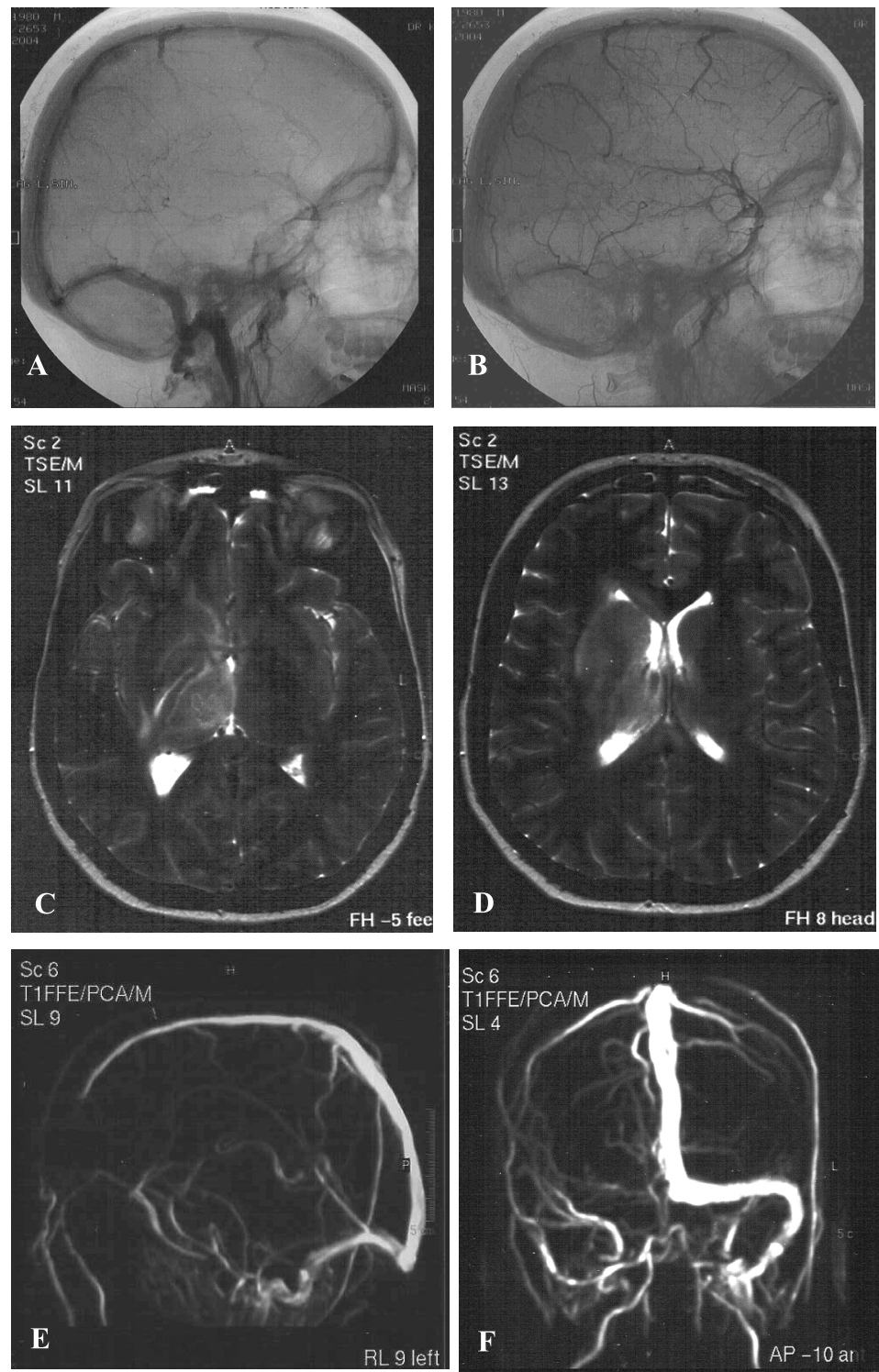

A, B, DSA (day 1) closure of sinus transversus, vena magna cerebri (Galen), vena cerebri interna and vena basalis Rosenthali. Drainage of cortical venous collectors preserved.

C,D, T2- weighted images (day 4)- hyperaemia, or cerebral turgescence of right-hand side basal ganglia and the thalamus, with an image of signal hypersensitivity, imitating cerebral ischemia.

E, MR venography - lateral image (day 4)- incomplete thrombosis of the sinus rectus, non-detectable flow in vena basalis Rosenthali.

F, Sagittal view on MR - venography - thrombosis of the right-hand side sinus transversus and sigmoideus and right vena jugularis interna.

Fig. 1. DSA, MRI + MR- venography- „Time of Flight-TOF“ 

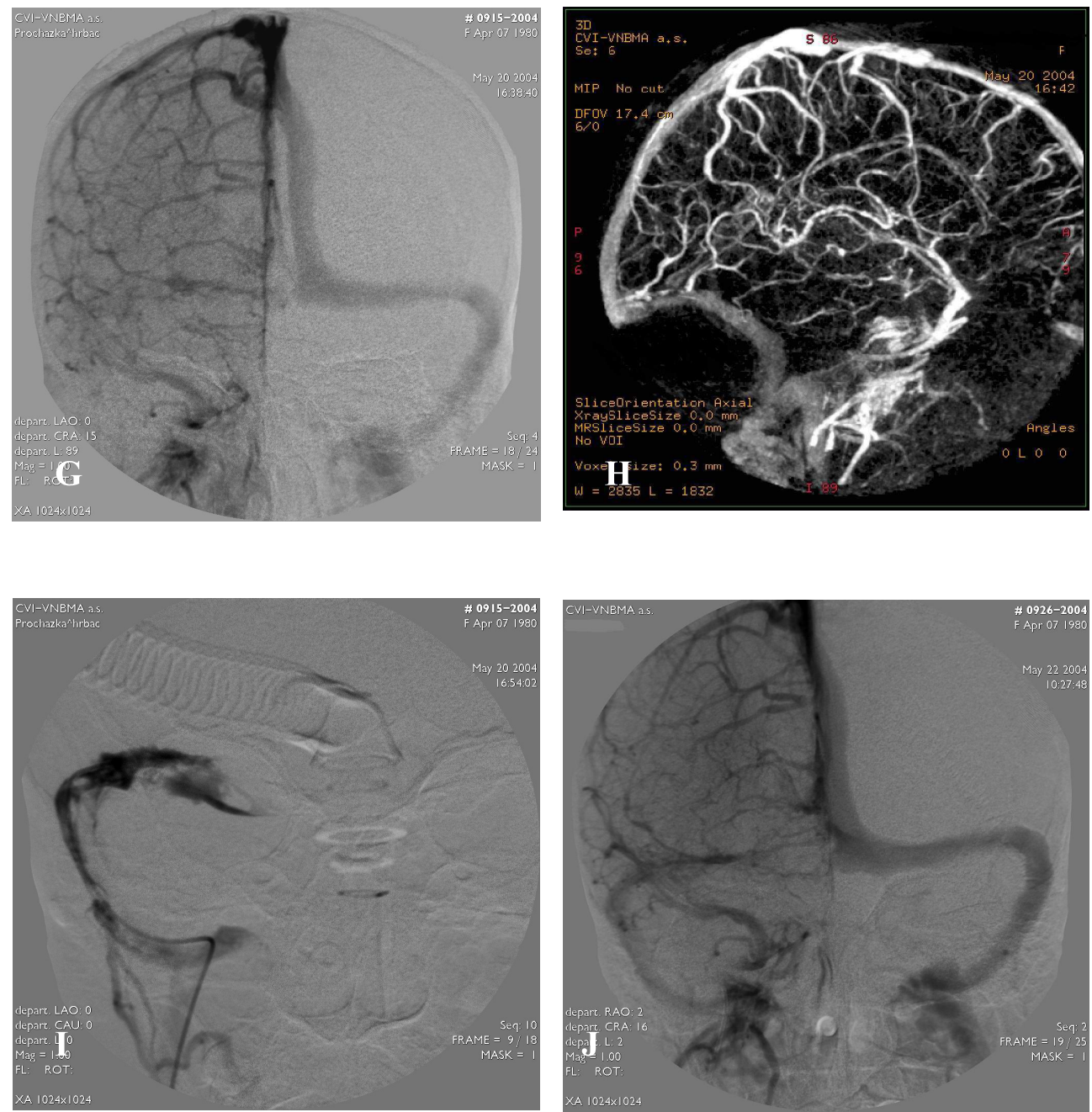

G, Sagittal view on DSA (day 5) - thrombosis of sinus transversus and sigmoid.

H, 3D-Xra digital rotational angiography, partial thrombosis, sinus rectus - "double railing" image, thrombosis of vena basalis Rosenthali. Closure of right sinus transversus and sigmoid.

I,4F-Vertebral Tempo Cordis JJ catheter inserted into right-hand sinus transversus, into the area of confluens sinuum, through a soft thrombus for introduction of local thrombolysis.

J, Sagittal view - DSA (day 7) - 48 hours of local thrombolysis - recanalization of the right-hand side sinus transversus and sigmoid.

Fig. 2. Interventional procedure +3D-Xra control angiography and MRI after thrombolysis 

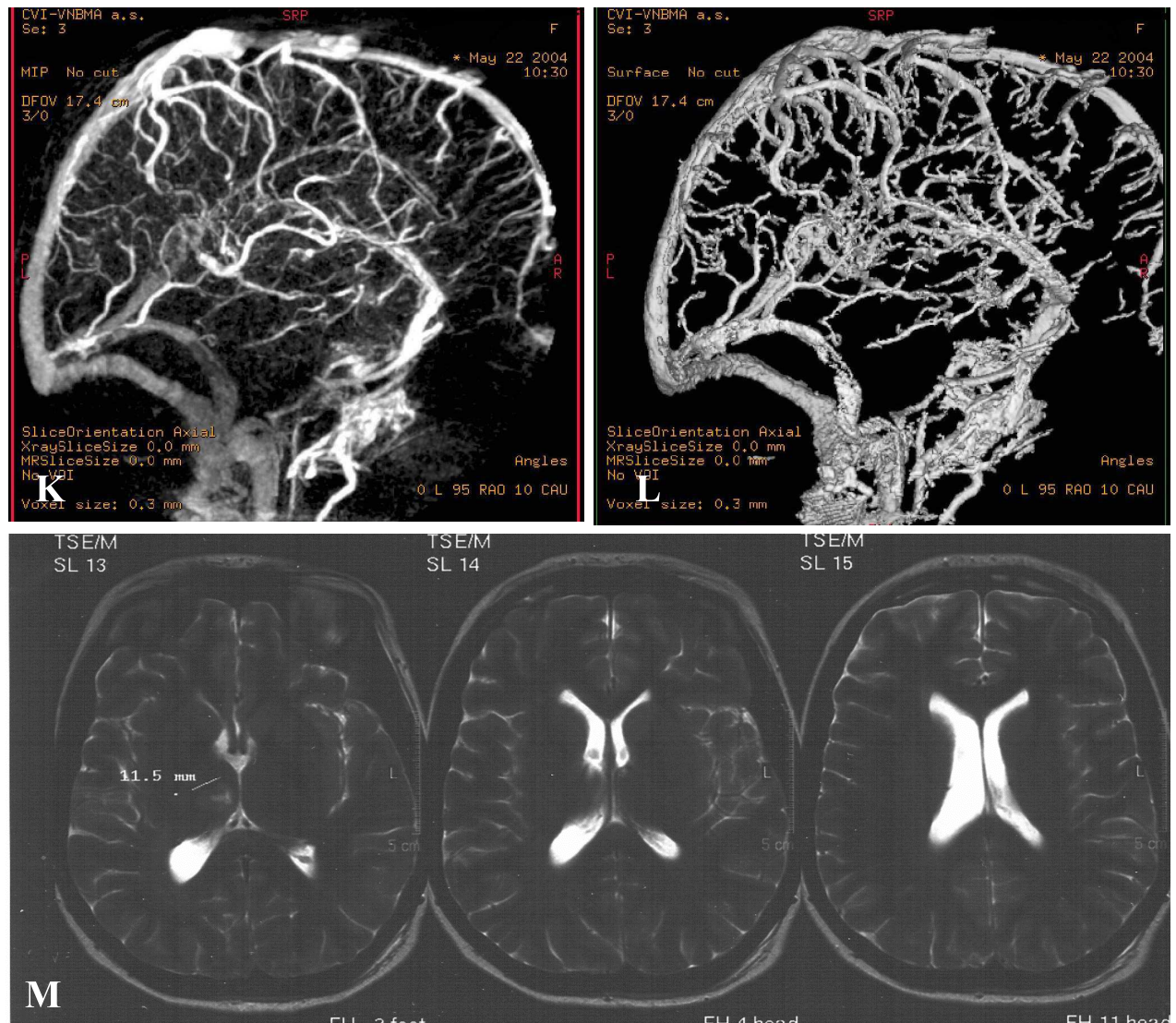

K, L, 3D-Xra digital rotational angiography with a complete recanalization of sinus rectus, vena magna cerebri, vena basalis Rosenthali and venae cerebri internae.

M, Control MRI - (1 month), with a minor venous infarction of pulvinar thalami on the right.

Fig. 2. Continues.

\subsection{Case report - CVT with malignant course}

Thirty-three-year-old female patient with a negative history and negative allergic history, using third-generation hormonal contraceptives for a short period of one month was examined for a headache localised in the right-hand side occipital area, accompanied with repeated vomiting. After five days of cephalgias, the patient observed worsening of the visual acuity, namely in the right eye. The patient was admitted at Neurology department due to an epileptic seizure. The subsequent CT examination was described as negative. On admission, the patient complained about inappetence and overall sickness after using individual tablets of the contraceptive. On the $8^{\text {th }}$ hospitalisation day, the patient suddenly lost consciousness, tonic stiffening of the limbs and jaw appeared, accompanied with sweating, and, having regained consciousness, the patient showed signs of overall confusion. Control CT examination was performed, with the image of squalid cortical areas and suspected subarachnoidal haemorrhage in the occipital area on the right, around 
sinuses. Within further two hours, the patient lost consciousness, accompanied with meningeal symptomatology and left-side hemiparesis.

The patient was referred for MRI examination, which revealed a massive cerebral venous thrombosis of all cerebral sinuses, with a closure of the deep vein system drainage in the diencephalic area and around basal ganglia (Fig. 3). After subsequently performed examinations, the patient was intubated in semi-comatose state and transferred to the interventional centre for an emergency endovascular procedure.

\section{Interventional procedure}

Under general anaesthesia, through a cannulation of right-hand side common femoral vein, we inserted 4F sheath Terumo and applied UF-Heparin $5000 \mathrm{U}$ i.a.. Through the sheath we inserted 4F Vertebral Aqua - Tempo (Cordis - Endovascular, JJ, Miami, FL) diagnostic catheter and proceeded with diagnostic angiography of the cerebral arteries. The AG revealed a significantly delayed capillary filling, and venous drainage of both hemispheres, as well as a complete thrombosis of sinus sagitalis superior, sinus transversus and sigmoideus on the right side, a complete closure of deep venous drainage - v. basalis Rosenthali, v. cerebri internae, v. magna cerebri and sinus rectus. We inserted a second 5F Terumo loader into the common femoral vein, and through it a second diagnostic Vertebral catheter, on Terumo loader (Radiofocus, Tokyo, Japan) we penetrated into v. jugularis interna on the right, through foramen jugulare into sinus sigmoideus and transversus on the right, up to the confluens sinuum area. We initiated the application of local thrombolysis in the dose of $1 \mathrm{mg}$ rt-PA/hr per 24 hours.

\section{Therapy at the Anaesthesiology-Resuscitation Department}

Patient was left on controlled artificial lung ventilation, on antibiotics (amoxyciline with clavulanic acid i.v., at the dose of 1,2 g every 8 hours), parenteral infusion therapy with crystaloids, glucose, massive anti-oedematous therapy, continuous local thrombolysis.

\section{Laboratory examination}

Antithrombin III 88..67, Leukocytes 15,7; Erythrocytes 4,40; Haemoglobin 13,6, Haematocrit 0,357; Thrombocytes 291; APTT 180 vt., Quick 19,4; INR 1,62; Fibrinogen 3,0.

\section{Control CT on the following day}

Significant progression of the cerebral oedema, faded basal cisterns, clouded structures of the mesencephalon, smoothened gyrification, clouded structure of the right basal ganglia, medium line without deviation, faded lateral ventricles, high density in sinus sagitalis superior and sinus rectus with proven thrombosis. Conclusion - manifestation of a diffusive oedema, together with thrombosis of cerebral sinuses.

\section{Neurological examination}

Patient without attenuation, on artificial lung ventilation without any spontaneous activity, no reaction to painful stimuli, stem reflexes not manifested, generalized hypotonic state with C5-C8, L2-S2 areflexia. Conclusion: areactive coma, without manifestation of stem reflexes, corresponding to cerebral death. The patient dies on basal therapy after 11 days of hospitalization.

\section{Pathology-anatomic finding}

see Fig. 4. The image confirms extensive cerebral venous thrombosis, cerebral oedema, mainly in the area of brainstem, without manifestations of intracerebral haemorrhage. 

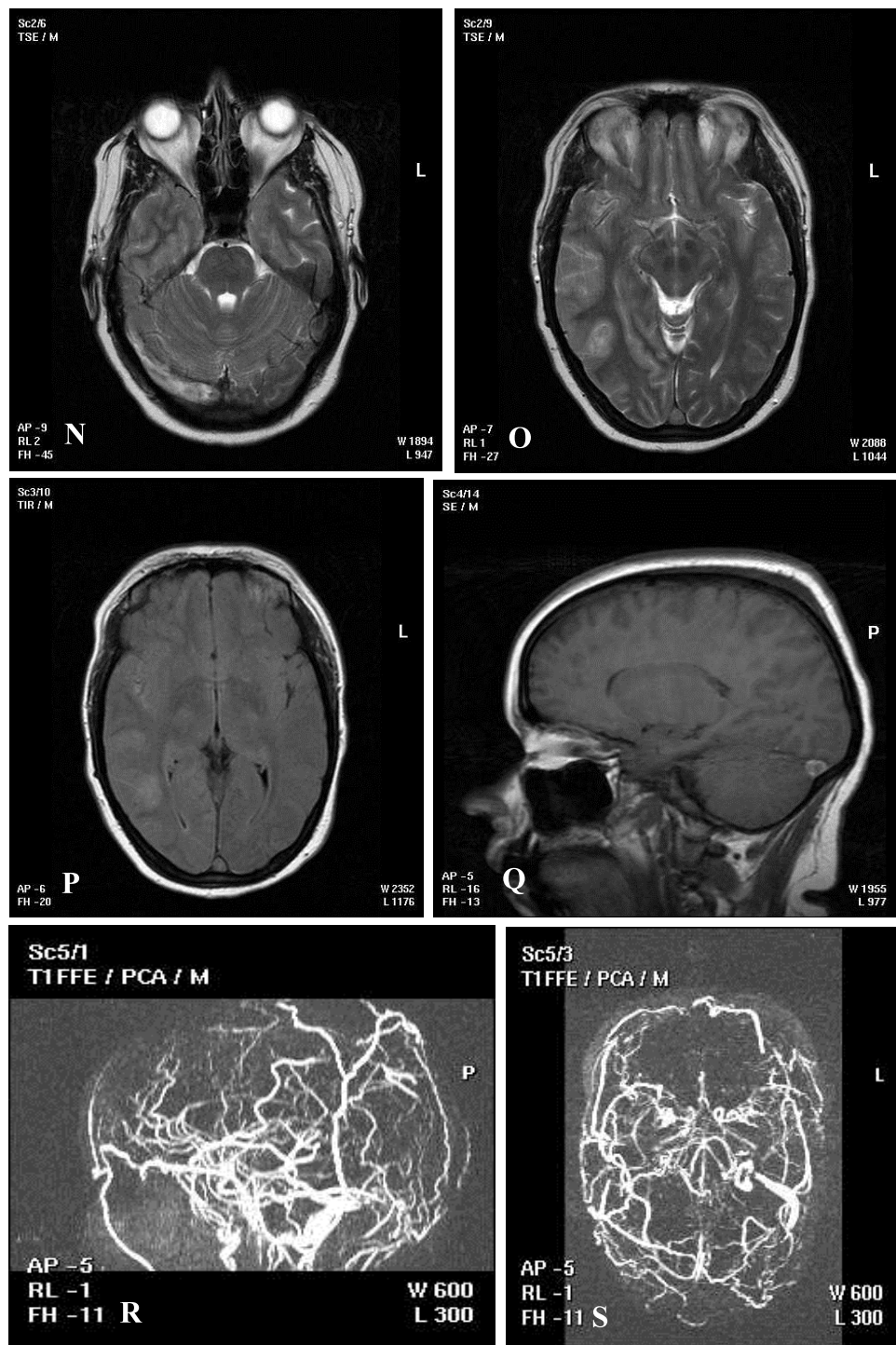

N, T1WI-MRI - axial scan with the image of hyperintense signal of sinus transversus thrombosis on the right and hyperaemia, or vasogenic dilatation of the right temporal lobe.

$\mathbf{O}, \mathbf{P}$ T1WI-MRI axial scan with the image of hyperaemia, or vasogenic inflation of the right temporal lobe.

Q, T1WI-MRI - image of "analogous delta sign" at the thrombosis at the area of division of the transversal sinus from confluens sinuum.

$\mathbf{R}, \mathbf{S}$, TOF- MR venography with findings of sinus sagitalis superior, sinus transversus and sigmoideus thrombosis on the right, deep vein system - sinus rectus, v. magna cerebri, vv. cerebri internae, and v. basalis Rosenthali.

Fig. 3. MRI examination and MR venography - (TOF) - sub-acute stage 

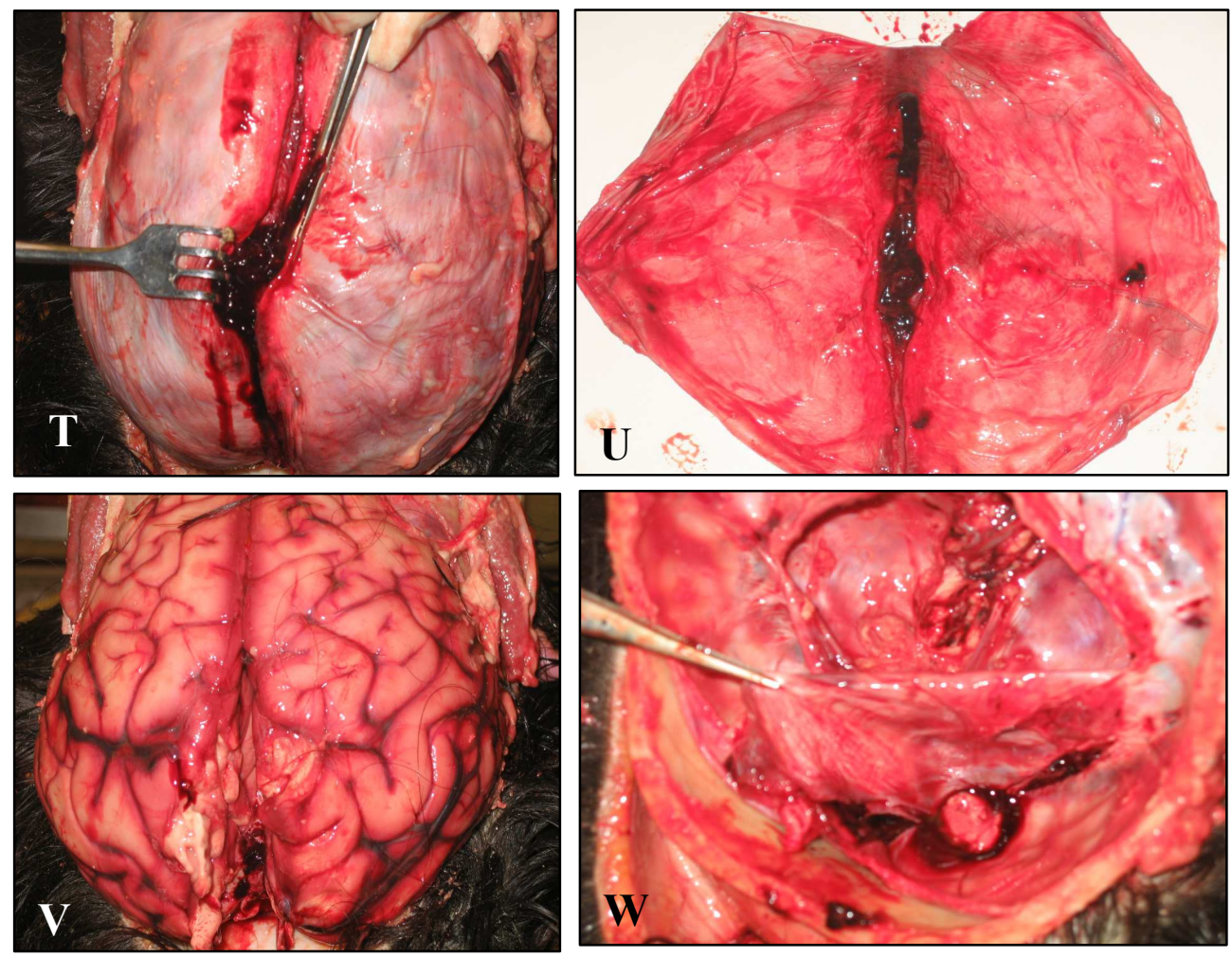

$\mathrm{T}, \mathrm{U}$ Thrombosis of sinus sagitalis superior as seen after opening of the sinus and removal of the hard meninges

V Thrombosis of confluens sinuum and sinus rectus orifice, thrombosis of Labe collector on the right and cortical veins parietally on the left

$\mathbf{W}$ Thrombosis of perimesenphalic veins with hyperaemia in the area of medulla oblongata

Fig. 4. Pathology-anatomic finding

\section{Results}

We present eight cases of cerebral venous thrombosis in a group of young women (aged between 18.7 and 39.3 years, mean age 28.1 years), who were hospitalized between April 2004 and October 2005.

The most frequently observed manifestations of CVT (see Table 1) were headache $(100 \%)$ and vertigo $(87,5 \%)$. The most frequently detected objective findings were movement disorders - central hemiparesis or quadruparesis $(75 \%)$, the same percentage applies to spasms, behavioural disorders, altered consciousness, sensoric disorders and aphasias (25\%). CT and MRI examinations (see Table 3,4) showed venous infarction or vasogenic inflation in $62.5 \%$ and presence of petechial haemorrhage in $25 \%$. Digital subtraction 3D-XR venography most frequently confirmed a combination of occlusions of sinus transversus and sigmoideus $(75 \%)$, sinus sagitalis superior $(62,5 \%)$, cortical veins $(62,5 \%)$ and deep venous system $(50 \%)$. 
The outcomes of the therapy were excellent in seven patients receiving the basic treatment. The treatment included administration of a combination of low weight molecular heparin in the treatment dose and subsequent coverage with warfarin. In three patients with insufficient effect of LMWH, we used local thrombolysis Actilyse ${ }^{\circledR}$ (rt-PA). One of the women died, despite acute thrombolysis and complex therapy. The results of coagulation tests (see Table 6) showed the presence of several thrombophilic risk factors in all women in our group. Homozygous form of the MTHFR-C677T gene mutation was detected in three patients, two patients had a mutation of the gene for PAI-1 in homozygous form. A combination of both homozygous forms was detected in one patient, the combination was present in heterozygous forms in two patients. The tests further detected an elevated level of factor VIII in three patients, and five of the patients showed a deficit of protein S, always in combination with mutations of the gene responsible for MTHFR-C677T, three of these were present in homozygous form.

\section{Discussion}

The first clinical and pathological finding of cerebral venous thrombosis was described by Ribs in 1825 in a 45-year-old male patient with generalized malignant process. Without the possibility of angiography imaging, the diagnosis was determined on the basis of clinical findings - progreding headaches, oedema of the eye papilla, spasms, focal deficit, coma, and was most usually confirmed with pathology-anatomical findings of thrombosis in the area of dural sinuses, accompanied with haemorrhagic infarsation. In 2001, an important study "International Study of Cerebral Vein Thrombosis" - ISCVT was published; the study prospectively monitored data of 624 patients with this diagnosis. (2)

Deep vein system, including vv. cerebri internae, v. basalis Rosenthali, v. magna cerebri and sinus rectus, responsible for the drainage of diencephalon, basal ganglia and deep structures of the white matter of hemispheres, is usually affected in $10 \%$ of cerebral venous thromboses. More serious clinical cases, including hemipareses and quadrupareses are caused by compression of capsula interna, with unilateral of bilateral infliction of the thalami or basal ganglia, and can be diagnosed with non-invasive examinations, e.g. CT or MRI under the image of the oedema or haemorrhagic infarction. Limitations of venous outflow result in cerebral hyperaemia, mostly detected on MRI in patients with CVT $(3,4,5)$. The diagnosis of CVT in our group of patients was confirmed with MRI imaging, MR venography and subsequently also with digital subtraction angiography. Liang et al. confirm the importance of three-dimensional imaging of magnetic resonance MP-RAGE venography, supported with the use of contrast, in the diagnostics of thromboses in the area of dural sinuses. This method was also very useful in our patient group. (6) As an alternative diagnostic procedure for CVT it is also possible to perform CT venography, together with the subtraction of bone structures "Mathed Mask Bone Elimination" (MMBE). (7) 3D-Xra-digital rotation venography provides an excellent alternative, with the possibility of imaging the speed and direction of the flow in a normal section of the venous system, as well as in partially thrombotized parts of dural sinuses and deep vein system.

The treatment of patients with intracranial venous thrombosis depends on the timeliness of the clinical suspicion of CVT and subsequent confirmation of the diagnosis with imaging techniques. Purdon Martin and Sheehan (1941) were the first to recommend anticoagulation therapy for the treatment of CVT. The treatment with heparin is currently considered as a treatment of choice in patients with CVT. (2) However, the effect of heparin may be too 
slow, especially in patients with rapidly progreding symptoms and involvement of most of the dural sinuses and deep venous system. This patient population should be referred for thrombolytic treatment, as the overall mortality of these patients reaches $10 \%$. (8-11) Our current experiences also point towards the possibility of mechanical revascularization of the obstructed venous bed, using the techniques of rheolytic thrombectomy and mechanical disturbance of the thrombus with balloon catheters. $(12,13)$

Thrombophilic states are commonly observed in $25-35 \%$ of patients with venous thrombosis. $(14,15)$ Hormonal contraceptives are currently used by more than 100 million women. Shortly after their introduction in 1960s, an increased incidence of thrombotic vascular complications was observed (16-18), together with an interaction of hormonal contraceptives and haemocoagulation system. Increased activity of coagulation factors VII, VIII, X and fibrinogen is a common finding in most cases. (19) Martinelli et al. in their work define the risk of onset of cerebral venous thrombosis in users of hormonal contraceptives OR 6,1 95\% CI $(3,3-11,00)$. This potential risk may be further intensified by congenital haemostatic disorders. (20)

Peroral contraceptives induce extensive changes in the fibrinolytic system. The levels of plasminogen and plazmin-alfa2-antiplazmin complex are elevated, also the activity of tissue activator of plasminogen (tPA) is increased, at the same time, the level of antigen inhibitor of the plasminogen-I activator (PAI-I) and the PAI-I activity are decreased, and many other changes occur. The fibrinolysis in the users of contraceptives is elevated, which is most probably caused by the response and compensation of the prothrombogenic state, caused by hormonal preparations. These changes are identical in preparations containing levonorgestrel, as well as third-generation gestagens. (21) Genetically conditioned thrombophilic states of the fibrinolytic system (PAI-I) increase the potential risk of the onset of thrombosis in HAK users. An increased activity and clustering of platelets was observed. (22)

Hormonal contraceptives with third-generation gestagens are connected with an increased risk of venous thromboses, in comparison with previous generations of contraceptives. This risk is also present in women without $\mathrm{V}$ Leiden factor mutation or a positive family history. (23)

\section{Conclusion}

Our experience points towards the possibility of CVT onset in young women using hormonal contraceptives. This condition needs to be taken into account in cases of intracranial difficulties. CVT is most commonly manifested with headaches, vertigo and visual disorders. That is why the diagnosis should be considered when a sudden onset of such manifestations occurs in otherwise healthy young woman. The CT or MRI examinations should be directed towards the possibility of affection of the venous intracranial system. MRI and MR-venography or 3DX-RA venography significantly decrease the diagnostic process in patients with disorders of the deep venous cerebral system and a rapid development of symptoms. Direct endovascular thrombolysis, with the possibility of mechanical revascularization may dramatically improve the clinical course of patients with thrombosis of cerebral veins in patients with insufficient effect of anticoagulation therapy, associated with rapidly progreding disorders of consciousness. Thrombolytic therapy also decreases the occurrence of secondary complications following thrombolyses of cerebral veins, such as chronic intracranial hypertension with visual disorders or onset of arteriovenous shunts. $(24,25)$ Taking into account the incidence of these serious complications, we consider as essential, in compliance with recommendations of the Czech Society of 
Gynaecology and Obstetrics JEP, prior to administration of HAK, to perform a detailed analysis of personal and family history, and in indicated cases also a detailed examination of the presence of thrombophilic states. The significance of individual thrombophile mutations is inconsistent. Absolute contraindications for HAK usage include deficit of the antithrombin III, protein $\mathrm{C}$ deficit, homozygous form of $\mathrm{V}$ Leiden factor and combination of other thrombophile mutations. Other thrombophile mutations present a relative contraindication only. Screening examination of women prior to administration of HAK is not indicated. (26) However, in our study group, although we performed a detailed retrospective analysis, the personal and family history were negative in all patients. Considering this fact there arises the question of a facultative possibility of thrombophile examination covered by the patient, based on the patient's request, prior to administration of HAK.

As a certain surprise we may mention the high incidence of homozygous form of C677T in out study group $(37,5 \%)$, which may be in consistence with the findings of Martinelli et al., who proved the risk of CVT onset in users of hormonal contraceptives with hyperhomocysteinemia OR 19,5 95\% CI $(5,7-67,3)$. The levels of homocystein were not monitored in our patients. Other frequently observed findings included mutations of the plasminogen activator inhibitor gene (PAI-1) and deficit of protein S, which may be also present in combinations strengthening the prothrombogenic effect. On the other hand, we did not observe an incidence of V Leiden factor in patients with CVT, however this factor is frequently mentioned in literature as a significant thrombophilic risk factor.

\section{Tables}

\begin{tabular}{|c|c|c|c|c|c|c|c|c|c|}
\hline & $\mathbf{1 .}$ & $\mathbf{2 .}$ & $\mathbf{3 .}$ & $\mathbf{4 .}$ & $\mathbf{5 .}$ & $\mathbf{6 .}$ & $\mathbf{7 .}$ & $\mathbf{8 .}$ & Mean \\
\hline Age & 32.0 & 32.5 & 24.1 & 18.7 & 33.3 & 24.8 & 39.3 & 20.2 & 28.1 \\
\hline
\end{tabular}

Table 1. Age of patients included into the study

\begin{tabular}{|c|c|c|c|c|c|c|c|c|c|}
\hline Symptoms & 1. & 2. & 3. & 4. & 5. & 6. & 7. & 8. & $\%$ \\
\hline Headache & + & + & + & + & + & + & + & + & 100 \\
\hline Vertigo & & + & + & + & + & + & + & + & 87.5 \\
\hline $\begin{array}{c}\text { Central hemiparesis } \\
\text { and quadruparesis }\end{array}$ & & + & + & & + & + & + & & 62,5 \\
\hline Sight disorders & & & & + & + & & & & 25.0 \\
\hline Sensitivity disorder & & + & & & & + & & & 25.0 \\
\hline Behavioural disorder & & & & & & & + & + & 25.0 \\
\hline Aphasia & & + & & & & & + & & 25.0 \\
\hline Spasms & & & & & + & + & & & 25.0 \\
\hline Coma & & & + & & + & & & & 25.0 \\
\hline
\end{tabular}

Table 2. Subjective and objective manifestations on admission 


\begin{tabular}{|c|c|c|c|c|c|c|c|c|c|}
\hline CT/MR & $\mathbf{1 .}$ & $\mathbf{2 .}$ & $\mathbf{3 .}$ & $\mathbf{4 .}$ & $\mathbf{5 .}$ & $\mathbf{6 .}$ & $\mathbf{7 .}$ & $\mathbf{8 .}$ & $\mathbf{\%}$ \\
\hline $\begin{array}{c}\text { Venous infarction, } \\
\text { vasogenic inflation }\end{array}$ & & + & + & & + & + & + & & 62,5 \\
\hline $\begin{array}{c}\text { Petechial } \\
\text { haemorrhage }\end{array}$ & & & & & + & & + & & 25,0 \\
\hline
\end{tabular}

Table 3. Parenchymatous lesions on CT/MRI

\begin{tabular}{|c|c|c|c|c|c|c|c|c|c|}
\hline & $\mathbf{1 .}$ & $\mathbf{2 .}$ & $\mathbf{3 .}$ & $\mathbf{4 .}$ & $\mathbf{5 .}$ & $\mathbf{6 .}$ & $\mathbf{7 .}$ & $\mathbf{8 .}$ & $\%$ \\
\hline $\begin{array}{c}\text { Sinus sagitalis } \\
\text { superior }\end{array}$ & + & & + & + & + & & + & & 62.5 \\
\hline $\begin{array}{c}\text { Sinus transversus, } \\
\text { sigmoideus }\end{array}$ & + & & + & + & + & + & + & & 75,0 \\
\hline Deep vein system & & & + & + & + & + & & & 50,0 \\
\hline Cortical veins & & + & + & + & + & + & & & 62.5 \\
\hline V.jugularis interna & + & & + & & & & & + & 37.5 \\
\hline Cerebellar veins & & & & & & + & & & 12.5 \\
\hline
\end{tabular}

Table 4. Occlusion of sinuses / cortical veins on DSA 3D- XR venography

\begin{tabular}{|c|c|c|c|c|c|c|c|c|}
\hline & 1. & 2. & 3. & 4. & 5. & 6. & 7. & 8. \\
\hline $\begin{array}{c}\text { Contraceptiv } \\
\text { es }\end{array}$ & + & + & + & + & + & + & + & + \\
\hline Treatment & $\begin{array}{c}\text { LMWH } \\
+ \\
\text { Wa }\end{array}$ & $\begin{array}{c}\text { LMWH } \\
+ \\
\text { Wa }\end{array}$ & $\begin{array}{c}\text { LKT } \\
+ \\
\text { LMWH } \\
+ \\
\text { Wa }\end{array}$ & $\begin{array}{c}\text { LKT } \\
+ \\
\text { LMWH } \\
+ \\
\text { Wa }\end{array}$ & $\begin{array}{c}\text { LKT } \\
+ \\
\text { LMWH }\end{array}$ & $\begin{array}{c}\text { LMWH } \\
+ \\
\text { Wa }\end{array}$ & $\begin{array}{c}\text { LMWH } \\
+ \\
\text { Wa }\end{array}$ & $\begin{array}{c}\text { LMWH } \\
+ \\
\text { Wa }\end{array}$ \\
\hline Outcome & $\begin{array}{l}\text { Complete } \\
\text { recovery }\end{array}$ & $\begin{array}{l}\text { Complete } \\
\text { recovery }\end{array}$ & $\begin{array}{l}\text { Complete } \\
\text { recovery }\end{array}$ & $\begin{array}{l}\text { Complete } \\
\text { recovery }\end{array}$ & $\begin{array}{c}\text { Patient } \\
\text { died }\end{array}$ & $\begin{array}{l}\text { Complete } \\
\text { recovery }\end{array}$ & $\begin{array}{l}\text { Complete } \\
\text { recovery }\end{array}$ & $\begin{array}{l}\text { Complete } \\
\text { recovery }\end{array}$ \\
\hline Smoking & - & - & - & - & - & - & - & - \\
\hline
\end{tabular}

LMWH - Low Molecular Weight Heparin, Wa - warfarin, LKT - local continuous thrombolysis

Table 5. Therapy 


\begin{tabular}{|l|c|c|c|c|c|c|c|c|}
\hline & $\mathbf{1 .}$ & $\mathbf{2 .}$ & $\mathbf{3 .}$ & $\mathbf{4 .}$ & $\mathbf{5 .}$ & $\mathbf{6 .}$ & $\mathbf{7 .}$ & $\mathbf{8 .}$ \\
\hline $\begin{array}{l}\text { Factor V } \\
\text { Leiden }\end{array}$ & - & - & - & - & - & - & - & - \\
\hline MTHFR & ++ & ++ & +- & +- & - & ++ & +- & +- \\
\hline PAI-1 & - & - & ++ & - & - & ++ & +- & +- \\
\hline Factor VIII & - & - & - & + & + & + & - & - \\
\hline $\begin{array}{l}\text { Hyperhomo- } \\
\text { cysteinemia }\end{array}$ & + & - & - & - & - & - & - & - \\
\hline $\begin{array}{l}\text { Protein C } \\
\text { deficit }\end{array}$ & + & - & + & - & - & - & - & - \\
\hline $\begin{array}{l}\text { Protein S } \\
\text { deficit }\end{array}$ & + & + & - & + & - & + & - & + \\
\hline $\begin{array}{l}\text { Antithrombi } \\
\text { n deficit }\end{array}$ & - & - & + & - & - & - & - & - \\
\hline
\end{tabular}

Legend:- negative, +- heterozygous, ++ homozygous

-MTHFR- methylentetrahydrofolate reductase, PAI- plasminogen activator inhibitor

Table 6. Results of thrombophilic parameters

\section{References}

[1] Berenstein A, Lasjaunias P., Ter Brugge K.G: Venous Occlusive Disease. Surgical Neuroangiography vol. 2.1 Clinical and Endovascular Treatment Aspects in Adults. Second edition, Springer-Verlag Berlin Heidelberg, 135-152; 2004

[2] Ferro JM, Canhao P, Stam J, Bousser MG, for the ISCVT Investigators: Prognosis of cerebral vein and dural sinus thrombosis, results of the International Study on Cerebral Vein and Dural Sinus Thrombosis (ISCVT). Stroke 35; 664-670, March 2004

[3] Forbes P.N.K, Pipe JG, Heiserman JE: Evidence for cytotoxic edema in the pathogenesis of cerebral venous infarction. AJNR Am J Neuroradiology 22;450-455, March 2001

[4] Peeters E, Stadnik T, Bissay F, Schmedding E et Al.:Diffusion-weighted MR imaging of an acute venous stroke. AJNR Am J Neuroradiology 22;1949-1952,November 2001

[5] Ducreux D,Oppenheim C,Vandamme X et Al.:Diffusion-weighted imaging patterns of brain damage associated with cerebral venous thrombosis. AJNR Am J Neuroradiology 22;261-268, February 2001

[6] Liang L, Korogi Y, Sugahara T et Al: Evaluation of the Intracranial Dural sinuses with a 3D contrast-enhanced MP-RAGE sequence: prospective comparison with 2D-TOF MR venography and digital subtraction angiography. AJNR Am J Neuroradiology 22; 481-492, March 2001.

[7] Majoie CHB, van Straten M, Venema HW: Multisection CT Venography of the dural sinuses and cerebral veins by using matched mask bone elimination. AJNR Am J Neuroradiology 25; 787-791, May 2004.

[8] Rael JR, Orrison WW Jr., Baldwin N, Sell J: Direct thrombolysis of superior sagittal sinus thrombosis with coexisting intracranial hemorrhage. AJNR Am J Neuro-radiology 18;1238-1242, Aug 1997 
[9] Spearman MP, Jungreis ChA,Wehner JJ, et Al: Endovascular thrombolysis in deep cerebral venous thrombosis. AJNR Am J Neuroradiology 18; 502-506, Mar 1997

[10] Ciccone A, Canhao P, Falcao F, Ferro JM, Sterzi R: Thrombolysis for cerebral vein and dural sinus thrombosis. Cochrane Corner .Stroke 35; 000-001, Aug 2004

[11] Frey JL, Murro GJ, McDougall CG, Dean BL, Jahnke HK: Cerebral venous thrombosiscombined intrathrombus rtPA and intravenous heparin. Stroke 30; 489-494, February 1999

[12] Opatowsky MJ , Morris PP, Regan JD et Al: Rapid thrombectomy of superior sagittal sinus and transverse sinus thrombosis with a rheolytic catheter device. AJNR Am J Neuroradiology 20;414-417, March 1999.

[13] Dowd ChF, Malek AM, Phatouros CC, et Al: Application of rheolytic thrombectomy device in the treatment od dural sinus thrombosis: A new technique. AJNR Am J Neuroradiology 20; 568-570, April 1999.

[14] Provenzale JM, Barboriak DP,Allen NB, et Al: Antiphospholipid Antibodies: Findings at Arteriography. AJNR Am J Neuroradiology 19; 611-616, April 1998.

[15] Reuner KH, Ruf A, Grau A, Rickmann H, et AL: Prothrombin Gene G20210 $\rightarrow$ A transition is a risk factor for cerebral venous thrombosis. Stroke 29; 1765-1769, September 1998.

[16] Lüdemann P, Nabavi DG, Junker R, Wolff E, Papke K et AL: Factor V Leiden mutation is a risk factor for cerebral venous thrombosis, A Case -control study of 55 patients. Stroke 29; 2507-2510, December 1998.

[17] Cantu C, Alonso E, Jara A, Martínez Leticia et Al: Hyperhomocysteinemia, low folate and vitamin B12 concentrations, and methylene tetrahydrofolate reductase mutation in cerebral venous thrombosis. Stroke 35; 1790-1794, August 2004.

[18] Rosendaal, F.R., Helmerhorst, F.M., Vandenbroucke J.P. Oral contraceptives, hormone replacement therapy and thrombosis. Thromb Haemost 2001; 86: 112 -123.

[19] Bloemenkamp, K.W.M., Helmerhorst, F.M., Rosendaal, F.R., Vandenbroucke J.P., Thrombophilias and gynaecology. Best Practice\&Research Clinical Obsterics \& Gynaecology, vol.17, 3, 509-528, 2003.

[20] Martinelli I, Battaglioli T., Pedotti P. et al. Hyperhomocysteinemia in cerebral vein thrombosis. Blood, 2003; 102: 1363-1366.

[21] Norris, L.A, Bonnar, J., The effect of oestrogen dose and progesteron type on haemostatic changes in women taking oral contraceptives. Br J Obstet Gynaecol, 1996, 103: $261-267$.

[22] Kunz, F., Pechlander, C., Taberelli, M. et al. Influence of oral contraceptives on coagulation tests in native blood and plasma.Am J Obstet Gynaecol,1990,163:417- 420.

[23] World Health Organization. Cardiovascular disease and steroid hormone contraception. Report of a WHO Scientific group. WHO Technical Report Series, no.877. World Health Organization, 1998, Geneva.

[24] Stolz E, Gerriets T, Bödeker RH, Penzel MH,Kaps M: Intracranial venous hemodynamics is a factor related to a favorable outcome in cerebral venous thrombosis. Stroke 33; 1645-1650, June 2002.

[25] Phatouros C, Halbach VV, Dowd ChF, Lempert TE, Malek AM et Al: Acquired pial arteriovenous fistula following cerebral vein thrombosis. Stroke 30; 2487-2490, November 1999.

[26] Čepický P., Cibula D., Dvořák $K$, et al. Doporučení k předpisu kombinované hormonální kontracepce (CC). Aktualizace 2005. Čes.Gynek. 70; 2005; 4, 320-324. 


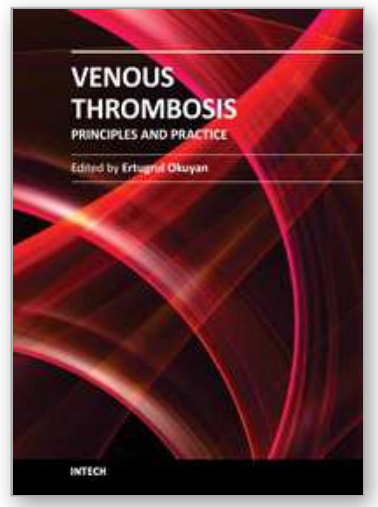

\author{
Venous Thrombosis - Principles and Practice \\ Edited by Dr. Ertugrul Okuyan
}

ISBN 978-953-307-885-4

Hard cover, 232 pages

Publisher InTech

Published online 05, January, 2012

Published in print edition January, 2012

According to Virchow's triad, venous thrombosis can occur as a result of one or more of three factors: changes in the dynamics of the blood flow, endothelial injury/dysfunction of the blood vessel and hypercoagulability. The blood in the veins is constantly forming microscopic thrombi that are routinely broken down by the body, and significant clotting can occur only when the balance of thrombus formation and resolution is altered. This book is a fresh synthesis of venous thromboembolism care and considers the opinions and studies from different fields of medicine. As venous thrombosis spectrum is wide and can affect many organ systems, from deep veins of the leg to the cerebral venous system, our intent is for this to be a comprehensive, up-to-date and readable book. We tried to present a synthesis of existing material infused with new ideas and perspectives and authors own clinical studies and even case-reports.

\title{
How to reference
}

In order to correctly reference this scholarly work, feel free to copy and paste the following:

Procházka Václav, Procházka Martin, Luubušký Marek, Procházková Jana and Hrbáč Tomáš (2012). Cerebral Venous Thrombosis in Patients Using Oral Contraceptives, Venous Thrombosis - Principles and Practice, Dr. Ertugrul Okuyan (Ed.), ISBN: 978-953-307-885-4, InTech, Available from:

http://www.intechopen.com/books/venous-thrombosis-principles-and-practice/cerebral-venous-thrombosis-inpatients-using-oral-contraceptives

\section{INTECH}

open science | open minds

\section{InTech Europe}

University Campus STeP Ri

Slavka Krautzeka 83/A

51000 Rijeka, Croatia

Phone: +385 (51) 770447

Fax: +385 (51) 686166

www.intechopen.com

\section{InTech China}

Unit 405, Office Block, Hotel Equatorial Shanghai

No.65, Yan An Road (West), Shanghai, 200040, China

中国上海市延安西路65号上海国际贵都大饭店办公楼 405 单元

Phone: +86-21-62489820

Fax: $+86-21-62489821$ 
(C) 2012 The Author(s). Licensee IntechOpen. This is an open access article distributed under the terms of the Creative Commons Attribution 3.0 License, which permits unrestricted use, distribution, and reproduction in any medium, provided the original work is properly cited. 